\title{
Release of Peptide Cotransmitters in Aplysia: Regulation and Functional Implications
}

\author{
F. S. Vilim, ${ }^{1,3}$ E. C. Cropper, ${ }^{3}$ D. A. Price, ${ }^{2}$ I. Kupfermann, ${ }^{1}$ and K. R. Weiss ${ }^{3}$ \\ ${ }^{1}$ Center for Neurobiology and Behavior, College of Physicians and Surgeons, Columbia University, New York, New York \\ 10032, ${ }^{2}$ C. V. Whitney Laboratories, University of Florida, St. Augustine, Florida 32086, and ${ }^{3}$ Department of Physiology \\ and Biophysics, Mount Sinai School of Medicine, New York, New York 10029
}

To gain insights into the physiological role of cotransmission, we measured peptide release from cell B15, a motorneuron that utilizes ACh as its primary transmitter but also contains putative peptide cotransmitters, the small cardioactive peptides (SCPs) and the buccalins (BUCs). All stimulation parameters used were in the range in which B15 fires in freely moving animals. We stimulated neuron B15 in bursts and systematically varied the interburst interval, the intraburst frequency, and burst duration. Both peptides were preferentially released when B15 was stimulated at higher intra- or interburst frequencies or with longer burst durations. Across stimulation patterns, the amount of peptide released depended on the mean frequency of stimulation and was independent of the specific pattern of stimulation. The parameters of stimulation that produce a larger release of peptides correspond to those that evoke larger contractions. Large and frequent contractions are likely to fuse or summate, thus disrupting the rhythmic behavior mediated by the muscle innervated by motorneuron B15. Because the combined effect of the SCPS and BUCs is to accelerate the relaxation and shorten the duration of muscle contractions, these peptides reduce the probability of the disruptive fusion or summation of muscle contractions. Because these cotransmitters regulate an aspect of muscle contractions that is not controlled by acetylcholine (ACh), the primary transmitter of B15, we suggest that peptides and ACh form parallel but functionally distinct lines of transmission at the neuromuscular junction. Both types of transmission may be necessary to ensure that behavior remains efficient over a wide range of conditions.

Key words: neuropeptides; dense-core vesicles; peptide release; Aplysia; cotransmission; confocal immunocytochemistry; motorneuron; modulation; muscle contractions; feeding
In our companion paper (this issue), we presented direct evidence that modulatory peptide cotransmitters are released from the terminals of the ARC motorneuron B15 (Cohen et al., 1978) when it fires in physiologically relevant patterns. We also demonstrated that the small cardioactive peptides (SCPs), which act postsynaptically to increase muscle contraction amplitude and relaxation rate (Lloyd et al., 1984, 1987; Cropper et al., 1987), and the buccalins (BUCs), which act presynaptically to reduce contraction amplitude by decreasing acetylcholine (ACh) release (Cropper et al., 1988, 1990a; Phares and Lloyd, 1992; Vilim et al., 1994), are costored in the same dense-core vesicles (DCVs) in B15 terminals. Our observation that partially antagonistic peptides are coreleased is not easily reconciled with the commonly held notion that the function of cotransmitters is to amplify the action of primary transmitters (Lundberg and Hokfelt, 1983; Hokfelt, 1991; Horn, 1992). Specifically, although it is true that the SCPs enhance the size of contractions produced by ACh released from the motorneuron terminals, the BUCs serve to depress their size. Thus, the joint action of these neuropeptides does not appear to be an effective means of amplifying the action of ACh. Furthermore, the SCPs change the relaxation rate of muscle contractions, a characteristic that is not regulated by ACh. This suggests that these peptides, rather than acting as amplifiers, may actually act

Received June 24, 1996; revised Sept. 20, 1996; accepted Sept. 24, 1996.

This work was supported in part by National Institutes of Health Grants MH36730, MH50235, and GM32009 and the Hirschl Foundation.

Correspondence should be addressed to Klaudiusz R. Weiss, Department of Physiology and Biophysics, Mt. Sinai School of Medicine, 1 Gustave Levy Place, New York, NY 10029.

Copyright (C) 1996 Society for Neuroscience $0270-6474 / 96 / 168105-10 \$ 05.00 / 0$ jointly to produce a type of regulation of muscle contractions that is distinct from, and parallel to, the regulation exerted by $\mathrm{ACh}$, the actions of the latter being limited to the regulation of the size of muscle contraction.

The notion that peptide cotransmitters function as amplifiers is often tied to the idea that this amplification occurs under conditions of high frequencies of stimulation, perhaps physiologically abnormal frequencies, when the primary transmitters fail to exert their desired action (Hokfelt, 1991). Although the data presented in our companion paper (this issue) indicated that peptides are released under physiologically relevant rates of motorneuron stimulation, the frequencies we used were in the upper range of those recorded in normally feeding animals. However, if our suggestion that peptides transmit information that is complementary but distinct from ACh is indeed correct, we may expect that peptides will be released over a wide range of firing frequencies of the motorneurons. In this paper, we present a series of studies of peptide release under different rates and patterns of motorneuron firing, but always within physiological ranges. Findings presented in this paper are consistent with a hypothesis (Weiss et al., 1992) that peptide cotransmitters in this system function to increase the efficiency of behavior over a wide range of demands imposed on the system, e.g., the level of hunger and the characteristics of food that the animal is ingesting.

\section{MATERIALS AND METHODS}

Animals. Specimens of Aplysia californica were obtained from Marinus and Marine Species Unlimited. The animals were maintained at $14-16^{\circ} \mathrm{C}$ on a $12 \mathrm{hr}$ light/dark cycle and fed every $3 \mathrm{~d}$. Animals in the range of $50-100 \mathrm{gm}$ were used for the morphology experiments, and animals in the 
range of 300-600 gm were used for release experiments. Isotonic $\mathrm{MgCl}_{2}$ ( $25-50 \%$ body weight) was used to immobilize the animals, and all stages of the dissection were carried out in the animal's own hemolymph containing $\mathrm{MgCl}_{2}$.

Antibodies. The rabbit antibody to serotonin used for immunocytochemistry was a kind gift from Dr. Hadassah Tamir (Columbia University). The rat antibody to SCP used for immunocytochemistry was raised against $\mathrm{SCPb}$ coupled to bovine thyroglobulin using the carbodi-imide method described in the companion paper. The rabbit antibody to $\mathrm{SCPb}$ used for radioimmunoassay was a kind gift from Dr. H. R. Morris (Empire College). The rabbit antibody to BUC used for radioimmunoassay was raised against BUC A coupled to bovine serum albumin using the carbodi-imide method.

LM immunocytochemistry. The immunocytochemical procedure was the same as described in the companion paper. Briefly, the tissue was fixed in $4 \%$ paraformaldehyde and $0.2 \%$ picric acid overnight and was washed with distilled water to remove the fixative. The tissue was permeabilized using $50 \%$ ethanol overnight. The tissue was blocked with $10 \%$ normal donkey serum in RIA buffer (see below) and incubated in primary antibody for 4-7 d. After a $2 \mathrm{~d}$ wash in RIA buffer, the tissue was exposed to the secondary antibodies for $2 \mathrm{~d}$ (Jackson ImmunoResearch, West Grove, PA). After a $2 \mathrm{~d}$ wash in RIA buffer, the tissue was examined and photographed using a Molecular Dynamics (Sunnyvale, CA) confocal microscope equipped with an argon/krypton laser and a Sarastro imageprocessing station.

Radioimmunoassay. Peptide content was determined as described in the companion paper (this issue). Briefly, $\mathrm{SCPb}$ and desaminotyrosinated BUC A were iodinated $\left({ }^{125} \mathrm{I}\right)$ using the chloramine T method. Iodinated stocks were repurified using reverse-phase HPLC and diluted in RIA buffer $\left(154 \mathrm{~mm} \mathrm{NaCl}, 10 \mathrm{~mm} \mathrm{Na} \mathrm{HPO}_{4}, 50 \mathrm{~mm}\right.$ EDTA, $0.25 \mathrm{~mm}$ merthiolate, $1 \% \mathrm{BSA}, \mathrm{pH} 7.5$ ) to a final activity of $10,000-15,000 \mathrm{cpm} / 100 \mu \mathrm{l}$. Antibodies were diluted in RIA buffer so that $100 \mu \mathrm{l}$ bound up $\sim 50 \%$ of the counts in $100 \mu \mathrm{l}$ of iodinated peptide trace (with a sample volume of $50 \mu \mathrm{l}$ ). The reaction was carried out for $2-3 \mathrm{~d}$ at $4{ }^{\circ} \mathrm{C}$ and terminated by addition of $2 \mathrm{ml}$ of RIA charcoal $\left(10 \mathrm{mM} \mathrm{Na}_{2} \mathrm{HPO}_{4}, 0.25 \mathrm{~mm}\right.$ merthiolate, $0.25 \%$ activated charcoal, $0.025 \% 70,000 \mathrm{kDa}$ dextran, $\mathrm{pH} 7.5)$. After 15 min, the samples were spun to separate charcoal and supernatant. The supernatant, containing the bound peptide, was decanted and counted in a gamma counter. Standard curves were generated using serial dilutions of peptide in artificial seawater containing $1 \%$ BSA to prevent sticking. Each tube had half the peptide of the previous tube, and the sample volume in each tube was $50 \mu \mathrm{l}$ to match the volume of the drops in the experiments. A spreadsheet program (Kaleidagraph 2.1) was used to plot the standard curves, to convert counts bound to femtomoles of peptide in the unknowns, and to display the data as graphs. Because the RIAs are probably measuring the release of more than one peptide cotransmitter within a family (Price, 1990), the release of the family is referenced (i.e., $\mathrm{SCP}=\mathrm{SCPa}, \mathrm{b}$ and $\mathrm{BUC}=\mathrm{BUCa}, \mathrm{b}, \mathrm{etc}$.$) .$

Release preparation. The $\mathrm{ARC}-$ buccal ganglion preparation was isolated as described in the companion paper. Briefly, the buccal ganglion was pinned in a dish containing $25 \%$ isotonic $\mathrm{MgCl}_{2}$ to prevent spontaneous activity, and the nerve was passed through a slit in the side of the dish. The ARC was suspended outside the dish, and a combination of silicone grease (Dow Corning, Corning, NY) and parafilm was used to seal the slit in the dish and encase the ARC to prevent dehydration. The ARC was perfused through an artery, and the perfusate was collected (every $2.5 \mathrm{~min}$ ) as drops, directly into the tube used to measure the peptide content. The motorneuron was impaled with two independent glass microelectrodes, one for recording voltage and one for injecting current.

The temperature of the $\mathrm{ARC}$ was maintained at $15 \pm 0.5^{\circ} \mathrm{C}$ by cooling the room with an air conditioner. In the experiments determining the effect of temperature on peptide release from B15, the temperature was elevated by bringing a heat source (a soldering iron) near the preparation. The distance of the heat source to the ARC determined the extent to which the temperature was elevated. For the experiments examining the effects of BUC A, serotonin, and ACh on peptide release, the agents were introduced into the ARC via the perfusion line. The perfusing solutions were exchanged simply by turning the peristaltic pump off and transferring the perfusion inlet into the other solution, and then turning the perfusion line on again. This method maintained a constant rate of perfusion for the different perfusing solutions and the small dead volume $(<100 \mu \mathrm{l})$ enabled fairly rapid $(<5 \mathrm{~min})$ introduction of the agents.

A statistical analysis program (StatView 4.5) was used to perform a within-subjects repeated-measures ANOVA on relevant data to assess
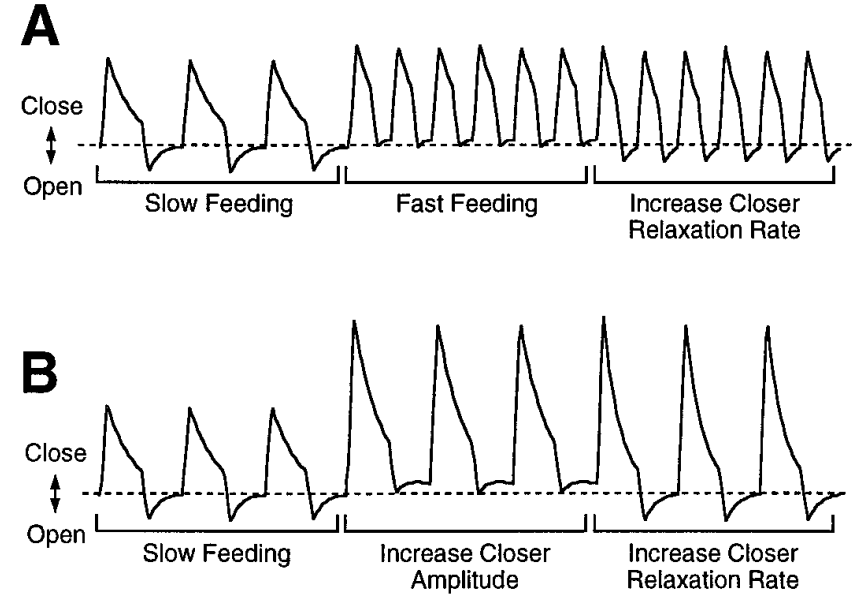

Figure 1. The hypothetical role of peptide cotransmitters in the generation of feeding behavior. The solid lines in $A$ and $B$ represent the position of the radula as the animal feeds. Below the dotted line the radula is open, and above the dotted line the radula is closed. In slow feeding, the radula initially closes in response to the contraction of a closer muscle. The closer muscle then relaxes, and the radula is opened by contraction of an opener muscle. The opener then relaxes, and the cycle is repeated. The radula must open and close if functional feeding is to occur. $A$ illustrates what could happen if the rate of feeding is increased while the amplitude and relaxation rate of both opener and closer muscles remains constant. During fast feeding, the contraction of the opener muscle overlaps with that of the closer and, therefore, the opener can no longer provide enough force to open the radula. Radula opening, and therefore functional feeding, can be restored if the closer muscle relaxation rate is increased. $B$ illustrates what happens if the radula closer amplitude is increased with no change in any of the other parameters. Again, the opener muscle is not able to generate enough force to open the radula, and feeding is ineffective. And again, opening and functional feeding can be restored if the closer muscle relaxation rate is increased. This hypothesis predicts that release of peptides should occur when contraction frequency or amplitude is increased.

the overall level of statistical significance. Individual comparisons were performed using paired $t$ tests. All reagents were obtained from Sigma (St. Louis, MO), except where noted otherwise.

\section{RESULTS}

\section{Stimulation paradigm and its rationale}

In this paper, we examine a possible function of peptide cotransmitters in regulating contractions of feeding musculature. Aplysia feed by means of a chitinous structure called the radula. The movements of the radula are controlled by a complex set of muscles that constitute an organ called the buccal mass. Buccal muscles open and close the radula to allow grasping of food. Once food is grasped, the radula moves toward the esophagus where food is released and then ingested. In order for feeding to remain efficient, certain phase and amplitude relationships must be maintained as feeding behaviors change in speed and magnitude. Although this appears to be a relatively simple task, it necessitates a complex adjustment of the movement.

The difficulties that an animal may encounter when changing the strength and or speed of feeding behavior and the possible role of peptides in solving the problem is presented in Figure 1. In normal feeding, the radula must open and close for functional feeding to occur. If the rate and strength of feeding movements are constant, this is easily achieved as shown in the left panel of Figure 1. In this figure, the solid lines represent the position of the radula as the animal feeds. Below the dotted line the radula is open, and above the dotted line the radula is closed. In slow 
feeding, the radula initially closes in response to the contraction of a closer muscle. The closer muscle then relaxes, and the radula is opened by contraction of the opener muscles. The opener then relaxes, and the cycle is repeated. Figure $1 A$ illustrates what could happen if the rate of feeding increased while the amplitude and relaxation rate of both opener and closer muscles remained constant. During fast feeding, contractions of the opener muscle overlap with those of the closer and, therefore, the opener can no longer provide enough force to open the radula. Radula opening, and therefore functional feeding, can be restored if the closer muscle relaxation rate is increased. Figure $1 B$ illustrates what happens if the amplitude of the contraction of the radula closer is increased with no concomitant change in the amplitude or relaxation rate of opener muscle contractions. Again, the opener muscle is not able to generate enough force to open the radula, and feeding is ineffective. Again, opening and functional feeding can be restored if the relaxation rate of the closer muscle is increased. In the ARC, the increase in relaxation rate can be accomplished by the postsynaptic actions of the SCPs (Cropper et al., 1988). However, the SCPs also act postsynaptically to increase contraction amplitude, which would tend to increase the duration of the relaxation phase of contractions. This SCP-induced increased contraction amplitude can be compensated for by the actions of the BUCs, which act presynaptically to depress contraction amplitude. Because the SCPs and BUCs are costored and coreleased, and consequently must act together, the net effect would be to produce contractions of roughly the same size, but which relax more quickly. We hypothesize that this increased relaxation rate would be necessary if contractions were brought closer together or if their amplitude were increased.

The ARC is a nonspiking muscle that contracts in response to ACh released from motorneuron terminals (Cohen et al., 1978; Lloyd and Church, 1994). The amplitude of contractions is related to muscle depolarization and the resulting inward calcium current (Brezina et al., 1994; Kozak et al., 1996). Thus, manipulations that produce changes in the ACh release from the motorneurons can be used to change contraction amplitude in a manner that mimics changes observed during feeding behavior. Similarly, changes in the patterns of motorneuron activation can be used to mimic changes in the frequency of feeding behavior. Figure 2 illustrates the specific manipulations that were used to produce changes in the size and frequency of muscle contractions in experiments in which we measured the release of peptides.

Figure $2 A$ shows the reference stimulation pattern $(12 \mathrm{~Hz}, 3.5$ sec on, $3.5 \mathrm{sec}$ off) that was observed for B15 in vivo during fast feeding (Cropper et al., 1991c). Figure 2B illustrates the manipulation used to change the frequency of contractions without altering other parameters of stimulation. This was achieved by changing interburst intervals (IBIs) while maintaining the same intraburst frequency (IF) and burst duration (BD). The manipulations used to produce contractions of different amplitudes are illustrated in Figure 2, $C$ and $D$. In Figure $2 C$, we changed the IF. Notice that both the duration of the burst and the interburst interval remain the same as in the reference pattern (Fig. $2 A$ ). An additional way to manipulate the size of muscle contractions, which takes advantage of the observation that contraction amplitude is correlated with the duration of motorneuron bursts, is illustrated in Figure 2D. Here, BD was changed, but both the IBI and the IF were the same as those used in the reference pattern (Fig. 2A).

Because each of the manipulations of motorneuron firing produces a change in the total number of action potentials delivered

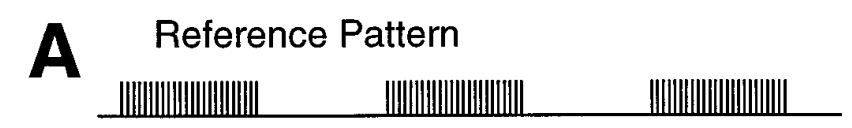

\section{B Change Interburst Interval}

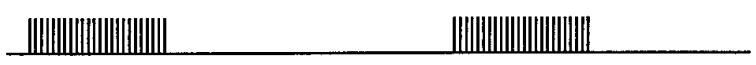
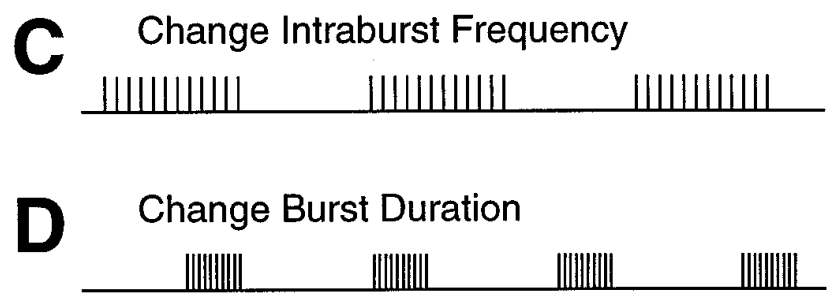

Figure 2. Diagram of the systematic changes made in stimulation parameters to test the predictions of the model. $A$ shows the reference stimulation pattern $(12 \mathrm{~Hz}, 3.5 \mathrm{sec}$ on, $3.5 \mathrm{sec}$ off) for motorneuron B15. The reference is identical for all three manipulations. $B$ illustrates the alteration of the IBI without changes in the IF or BD. $C$ illustrates the alteration of the IF without changes in the IBI or BD. $D$ illustrates alteration of the $\mathrm{BD}$ without changes in the IBI or IF. The difference in the total number of action potentials between the reference and the patterns shown in $B-D$ is compensated for by expressing peptide release per action potential.

in the 10 min stimulation period, total peptide release was divided by the total number of action potentials to give the release per action potential. Four 10 min stimulation periods followed by 15 min washout periods constituted a single experiment. An ABCA paradigm was used in which $\mathrm{A}$ was the reference condition and $\mathrm{B}$ and $\mathrm{C}$ were two manipulations of a single stimulation parameter. In the other half of the experiments, we used an ACBA paradigm to control for possible order effects. The release per action potential for the reference and experimental conditions was normalized by expressing each as a percent of the average of the three conditions (i.e., $B /[(A+B+C) / 3])$. The mean $\pm \mathrm{SE}$ of several experiments was then expressed as a function of the stimulation parameter that was changed.

\section{Stimulation parameters affect peptide release: IBI}

The IBI was varied from 3.5 to 5 and $7 \mathrm{sec}$, which is in the physiological range of the IBI seen in vivo (Cropper et al., 1990c). Figure $3 A$ shows the raw data from a single experiment in which the SCP content of the samples was measured. Motorneuron B15 was stimulated for four 10 min periods denoted by the black bars, where the first and fourth were reference stimulation conditions and the IBI increased during the second and third periods. The amount of SCP released is clearly reduced at the longer IBIs. A reduction is still apparent even after the peptide release is normalized to the number of action potentials and the ability of the preparation to release peptide cotransmitters. Figure $3 B$ shows normalized results from experiments in which SCP (5 experiments) and BUC (5 experiments) release was measured. Specifically, the mean $\pm \mathrm{SE}$ for each peptide is plotted for each IBI. These results clearly show that the amount of SCP and BUC released per action potential is greater at shorter IBIs (SCP: $F_{(2,8)}=112.3, p<0.0001$; BUC: $\left.F_{(2,8)}=27.83, p<0.0003\right)$. When release with a $5 \mathrm{sec}$ IBI was compared to the reference conditions, there was a significant decrease in the release of SCP $(p<0.0005)$ and BUC $(p<0.01)$. Further increase of the IBI 
A

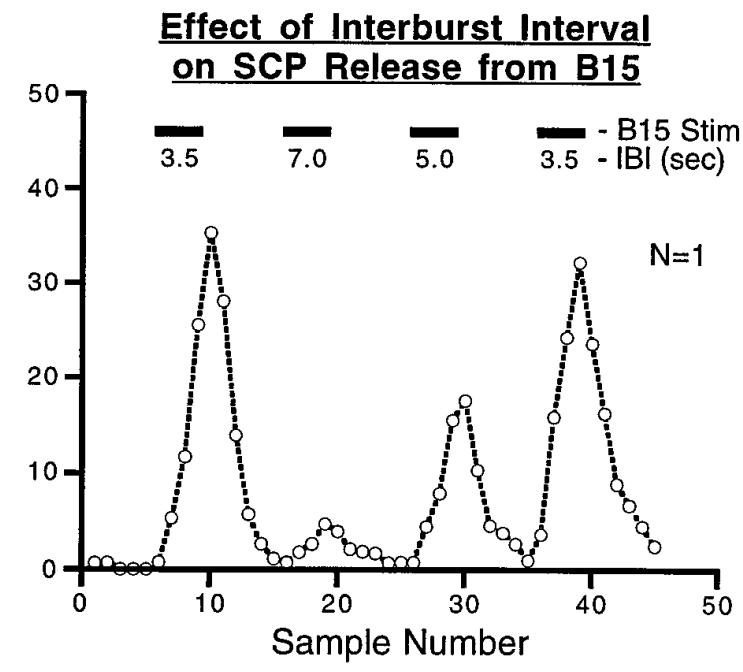

B

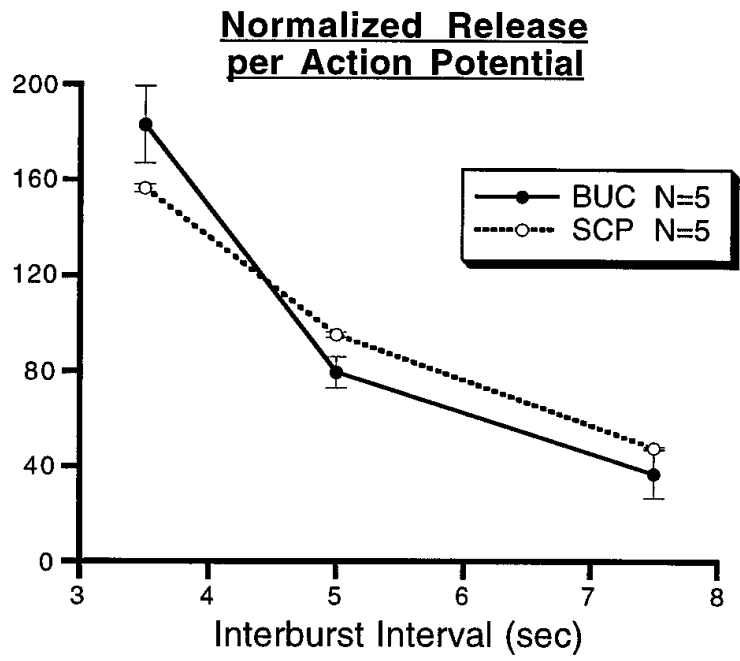

Figure 3. Effect of IBI on peptide release from B15. A, Results from a single experiment in which SCP release is measured at different IBIs while the IF $(12 \mathrm{~Hz})$ and the duration of bursts $(3.5 \mathrm{sec})$ are kept constant. SCP release decreases as the interval between bursts increases. $B$, The total released peptide at each of the three IBIs is corrected to give the release per action potential. The release per action potential for each of the three IBIs was normalized according to the average release for that experiment. The resulting percentage of average release from five separate experiments for each peptide was averaged for each of the three IBIs. For each of the peptides, the mean percent of average release \pm SE is plotted against the IBI. The results are similar for the two peptides and indicate that the amount of peptide released per action potential increases $(p<$ $0.005)$ as the duration between bursts decreases. The physiological range of IBIs for B15 varies from 3.5 to $10 \mathrm{sec}$ (or more).

from 5 to $7.5 \mathrm{sec}$ produced an additional decrease in the release of SCP $(p<0.002)$ and BUC $(p<0.002)$. Thus, an increase in peptide cotransmitter release per action potential parallels an increase in contraction frequency and, therefore, parallels an increase in the rate of feeding.

\section{Stimulation parameters affect peptide release: IF}

The IF was varied from 12 to 10 and $7.5 \mathrm{~Hz}$, which is in the physiological range of the IF seen in vivo (Cropper et al., 1990c). Figure $4 A$ shows the raw data from a single experiment in which the SCP content of the samples was measured. Motorneuron B15
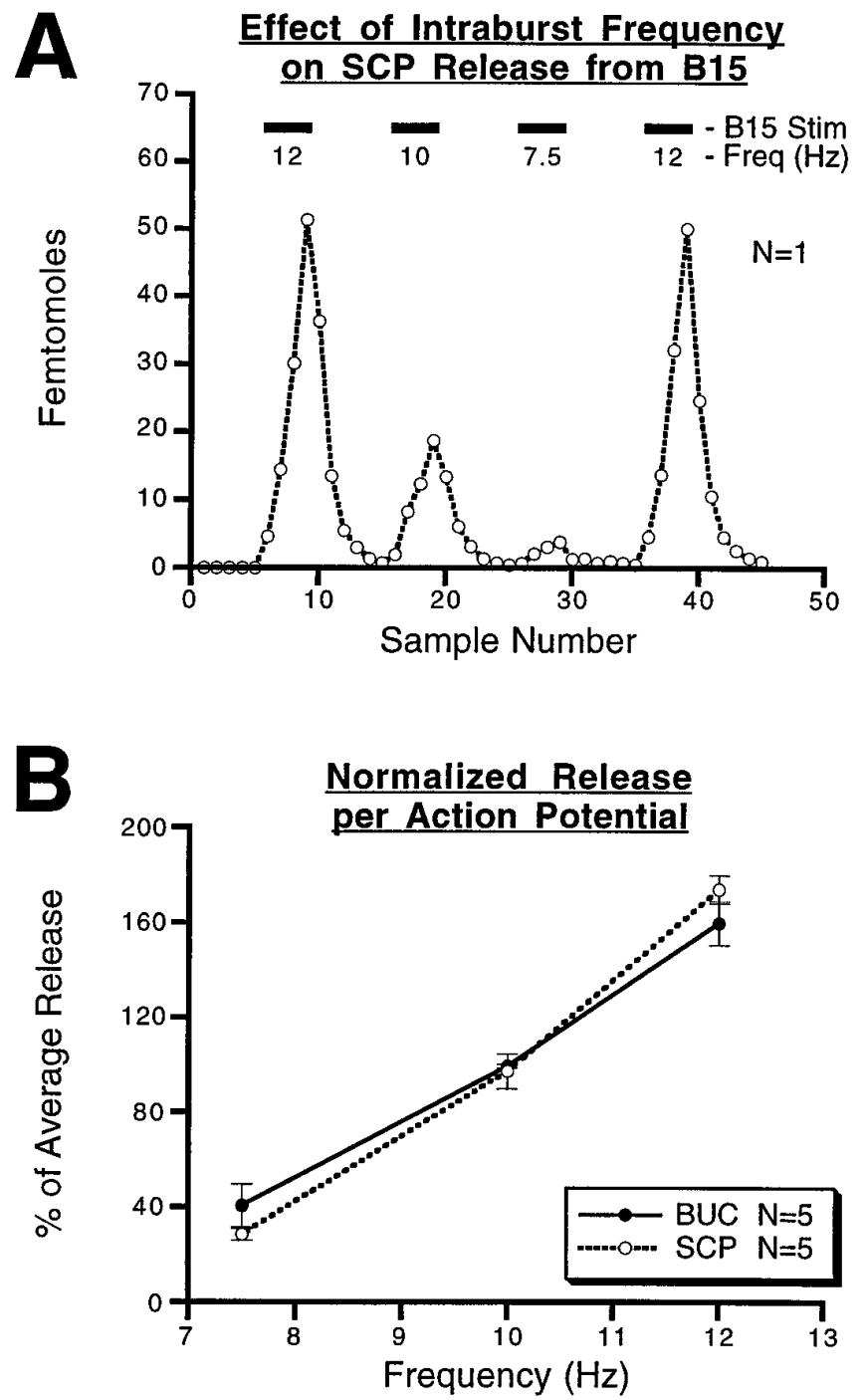

Figure 4. Effect of IF on peptide release from B15. A, Results from a single experiment in which SCP release is measured at three different intraburst frequencies while the duration of bursts $(3.5 \mathrm{sec})$ and the duration between bursts $(3.5 \mathrm{sec})$ are kept constant. SCP release is lower at the lower intraburst frequencies. $B$, The total released peptide for each of the three frequencies corrected to give the release per action potential. The release per action potential for each of the three frequencies was then normalized according to the average release for that experiment. The resulting percentage of average release from five separate experiments for each peptide was averaged for each of the three frequencies. For each peptide, the mean percent of average release \pm SE is plotted against the IF of stimulation. The results are almost identical for the two peptides and indicate that the amount of peptide released per action potential increases $(p<0.005)$ as the frequency of action potentials increases. The physiological range of firing frequencies for B15 varies between 7.5 and $12 \mathrm{~Hz}$.

was stimulated for four 10 min periods denoted by the black bars, where the first and fourth were reference conditions and the IF decreased during the second and third periods. The amount of SCP released is clearly reduced at lower frequencies. A reduction is still apparent even after the peptide release is normalized to the number of action potentials and to the total amount of peptides released. The normalized results for the release of SCP $(n=5)$ and BUC $(n=5)$ are summarized in Figure $4 B$, in which the average release of peptide \pm SE is plotted for each IF. These results clearly show that the amount of $\operatorname{SCP}\left(F_{(2,8)}=110.62, p<\right.$ 
$0.0001)$ and BUC $\left(F_{(2,8)}=38.25, p<0.0001\right)$ released per action potential is reduced at lower IFs. Individual comparisons revealed that compared to reference conditions a decrease of the IF to 10 $\mathrm{Hz}$ produced a significant decrease in the release of SCP $(p<$ $0.005)$ and $\mathrm{BUC}(p<0.005)$. When stimulation at $7.5 \mathrm{~Hz}$ was compared to that at $10 \mathrm{~Hz}$, a further decrease in the release of SCP $(p<0.002)$ and BUC $(p<0.006)$ was observed. Thus, an increase in peptide cotransmitter release per action potential parallels an increase in the contraction amplitude.

\section{Stimulation parameters affect peptide release: BD}

The BD was varied from 3.5 to 2.5 and $1.5 \mathrm{sec}$, which is in the physiological range of the BD seen in vivo (Cropper et al., 1990c). Figure $5 A$ shows the raw data from a single experiment in which the SCP content of the samples was measured. Motorneuron B15 was stimulated for four 10 min periods denoted by the black bars, where the first and fourth were reference conditions and the BD decreased during the second and third periods. The amount of SCP released is clearly reduced at shorter BDs. A reduction is still apparent even after the peptide release is normalized to the number of action potentials and the ability of the preparation to release peptide cotransmitters. The normalized results for SCP $(n=5)$ and BUC $(n=5)$ are summarized in Figure $4 B$, in which the mean $\pm \mathrm{SE}$ for each peptide is plotted for each BD. These results clearly demonstrate that the amount of SCP and BUC released per action potential is reduced at shorter BDs (SCP: $F_{(2,6)}=142.8, p<0.0001$; BUC: $\left.F_{(2,6)}=25.29, p<0.002\right)$. Individual comparisons revealed that compared to the reference pattern a $2.5 \mathrm{sec} \mathrm{BD}$ produced a significant decrease in the release of SCP $(p<0.01)$ and BUC $(p<0.005)$. A reduction of BD from 2.5 to $1.5 \mathrm{sec}$ produced a further decrease in SCP $(p<0.005)$ and BUC $(p<0.05)$. Again, a decrease in peptide release per action potential parallels a decrease in contraction amplitude.

\section{Temperature affects peptide release}

In addition to investigating the relationship between contraction size and/or frequency and the release of peptides as a function of the parameters of motorneuron stimulation, the effects of temperature on contraction size and peptide release were investigated. Our decision to investigate the effects of temperature was based on the following: (1) Aplysia live in waters where temperature varies from 14 to $21^{\circ} \mathrm{C}$ (Kupfermann and Carew, 1974); (2) we were able to demonstrate that temperature affects the size of muscle contractions (see below); and (3) temperature exerts an effect on B15 stimulation-induced elevation of cAMP, which presumably reflects peptide release (Whim and Loyd, 1990). We elevated the temperature of the ARC by placing a heat source at different distances from the preparation. ABCA and ACBA paradigms were used in which the stimulation parameters were held constant and the temperature was $15^{\circ} \mathrm{C}$ in $\mathrm{A}, 17^{\circ} \mathrm{C}$ in $\mathrm{B}$, and $19^{\circ} \mathrm{C}$ in $\mathrm{C}$. The results from a single experiment in which the BUC content of the samples was measured is shown in Figure $6 \mathrm{~A}$. Motorneuron B15 was stimulated for $10 \mathrm{~min}$ with the reference stimulation pattern (12 Hz $3.5 \mathrm{sec}$ on, $3.5 \mathrm{sec}$ off) during the periods denoted by the black bars. There is a clear reduction in the BUC released as the temperature was elevated. This effect was fully reversible, indicating that the decrement was not attributable to some nonspecific damage to the preparation. The combined results from eight experiments, four measuring each peptide, are shown in Figure $6 B$. The results show a significant decrease in $\operatorname{BUC}\left(F_{(2,6)}=45.94, p<0.0005\right)$ and $\operatorname{SCP}\left(F_{(2,6)}=52.3, p<\right.$ $0.0005)$ release as temperature is elevated. Individual compari-
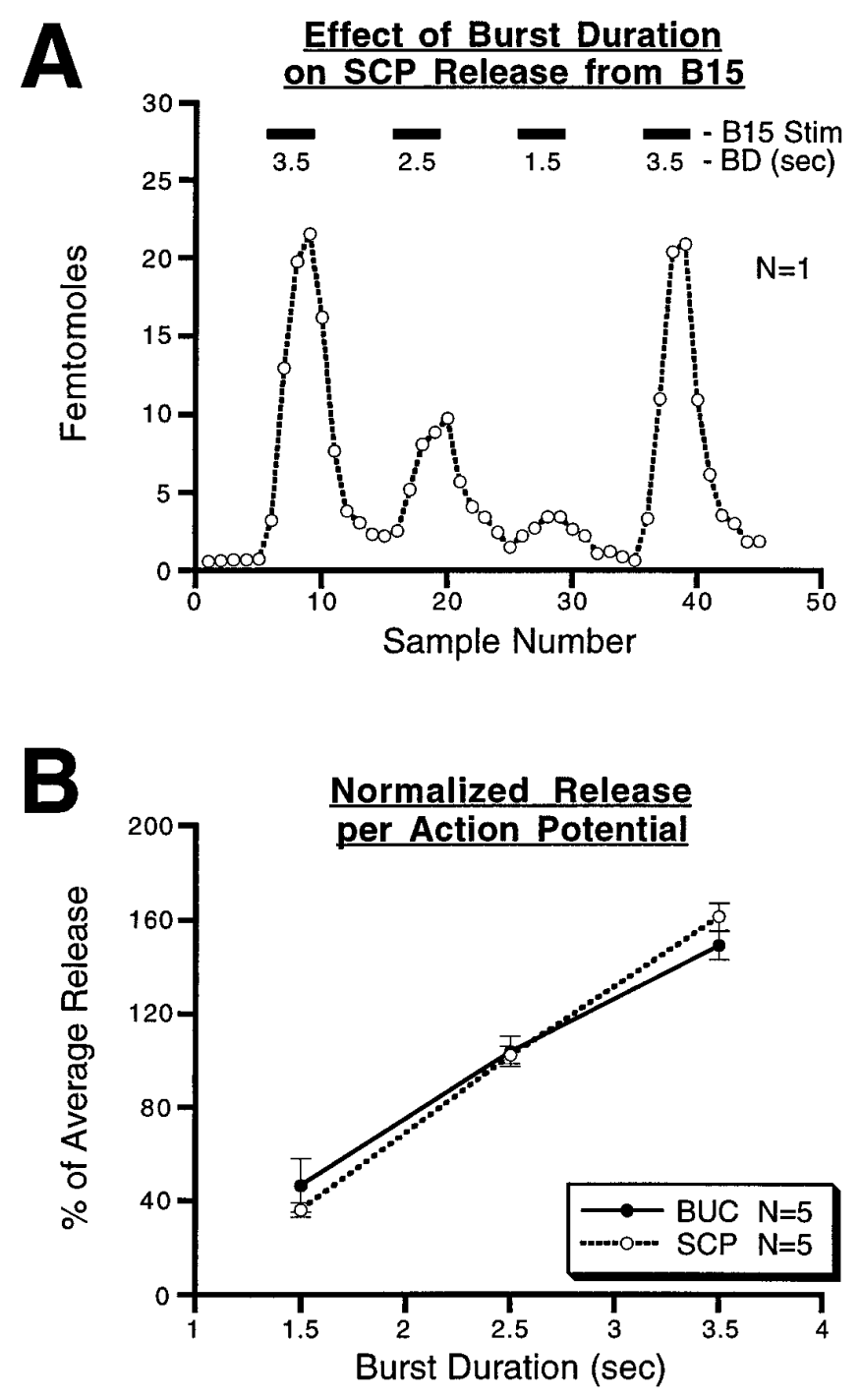

Figure 5. Peptide release is dependent on the BD. $A$, Results from a single experiment in which SCP release is measured at different BDs while the IF $(12 \mathrm{~Hz})$ and the duration between bursts $(3.5 \mathrm{sec})$ are kept constant. SCP release decreases as the BD is reduced. $B$, The total released peptide for each of the BDs was corrected to give the release per action potential. The release per action potential for each of the three BDs was then normalized according to the average release for that experiment. The resulting percentage of average release from four separate experiments for each peptide was averaged for each of the three BDs. For each peptide, the mean percent of average release $\pm \mathrm{SE}$ is plotted against the BD. The results are almost identical for the two peptides and indicate that the amount of peptide released per action potential increases $(p<0.005)$ as the duration of the burst increases. The physiological range of BD varies from 2 to $4 \mathrm{sec}$ for B15.

sons revealed that at $17^{\circ} \mathrm{C}$ release of SCP $(p<0.002)$ and BUC $(p<0.01)$ were significantly lower than at $15^{\circ} \mathrm{C}$. When we compared release at $19^{\circ} \mathrm{C}$ to release at $17^{\circ} \mathrm{C}$, a further significant decrease in peptide release was observed (SCP: $p<0.05$; BUC: $p<0.02$ ). Figure $7 B$ also shows that the contraction amplitude, measured at 3 min intervals to minimize peptide release and action, also decreases as the temperature increases. As with the results obtained by varying contraction amplitude with stimulation parameters, an increase in peptide cotransmitter release parallels an increased contraction amplitude resulting from a decrease in temperature. Because animals are exposed to a similar range of 

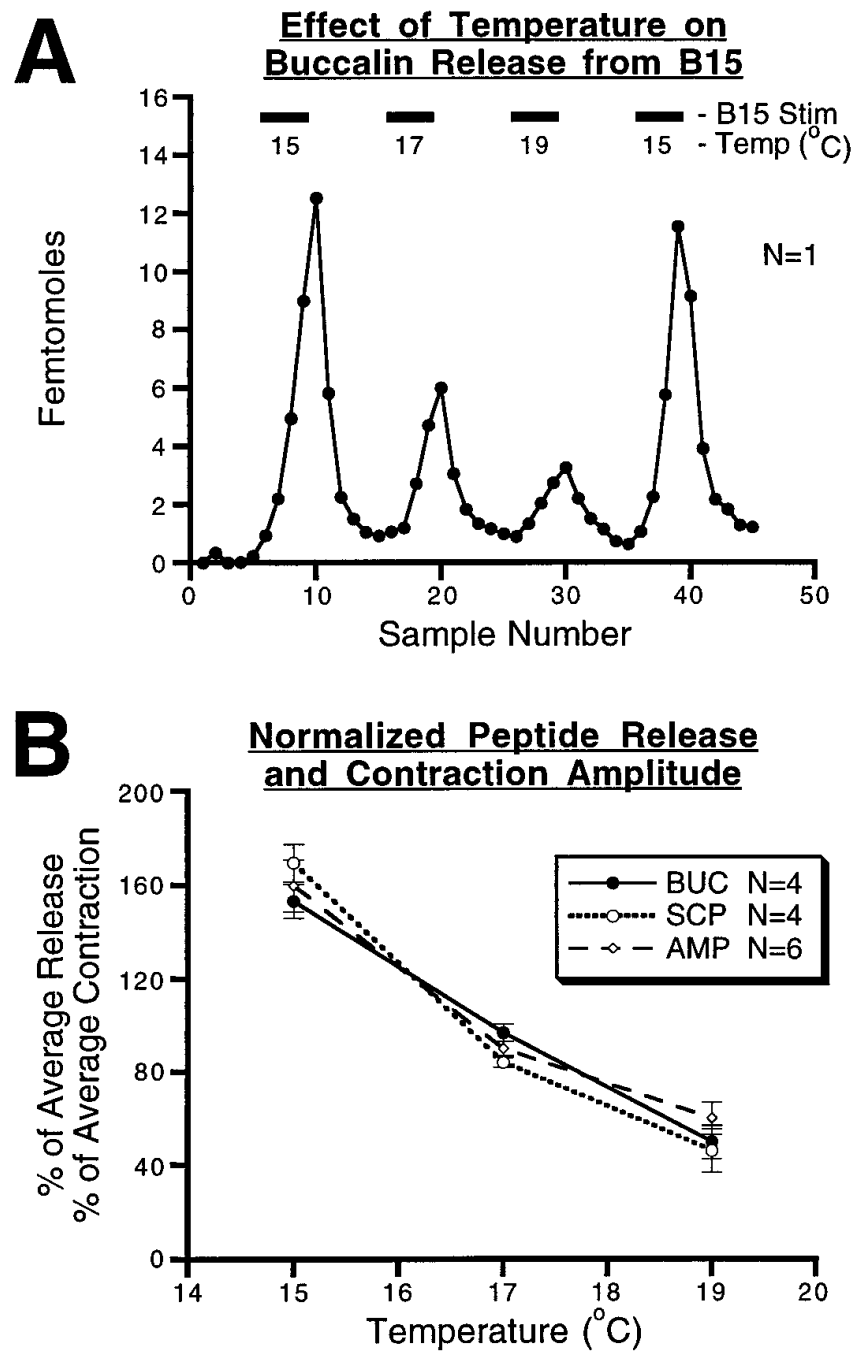

Figure 6. Effect of temperature on peptide release from B15. A, Results from a single experiment in which BUC release is measured at three different temperatures while stimulation parameters are kept constant. The BUC release decreases as the temperature is increased. $B$, The peptide released or the contraction amplitude at each temperature within an experiment was normalized to the average release or average contraction amplitude of that experiment. The resulting percentage of average release from eight separate experiments, four for BUC and four for SCP, was averaged for each peptide at each of the three temperatures and plotted against the temperature. The results are similar for the two peptides: they indicate that the amount of peptide released per action potential increases $(p<0.005)$ as the temperature decreases. The percent of average contraction amplitude from six separate experiments was averaged and plotted against the temperature. Peptide release and contraction amplitude show a remarkably similar relationship with temperature. The animals are normally housed at $15^{\circ} \mathrm{C}$.

temperatures in the wild (Kupfermann and Carew, 1974), peptides may also play a role in making behavioral compensations that may be needed to ensure proper functioning in different temperatures.

\section{Serotonin facilitates peptide release}

Contractions of the ARC muscle are modulated not only by peptides present in the motorneurons but also by a pair of modulatory serotonergic neurons, the metacerebral cells (MCCs). In the ARC muscle, the action of serotonin is virtually identical to that of the SCPs, i.e., both serotonin and the SCPs potentiate

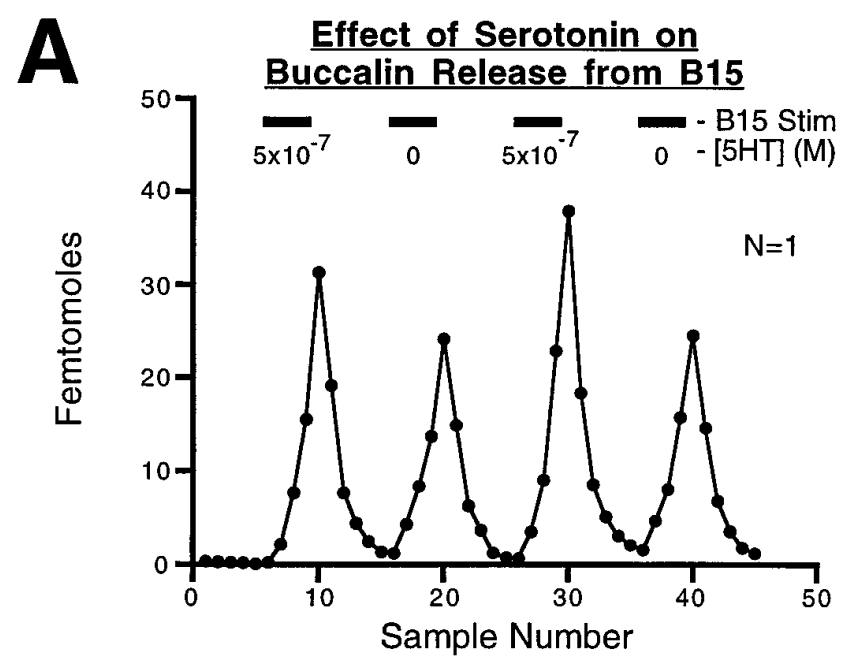

B

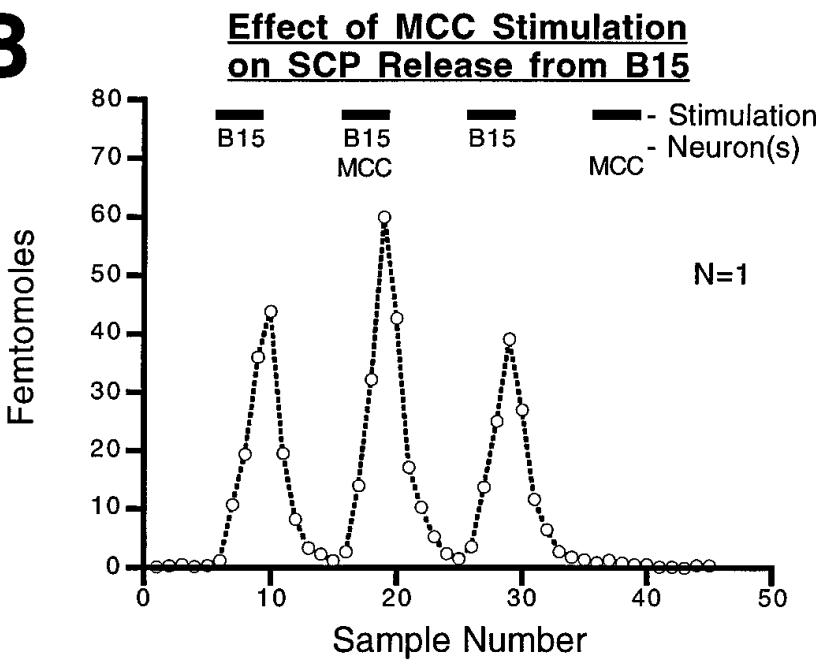

Figure 7. Effect of serotonin and MCC stimulation on peptide release from B15. $A$, The results from a single experiment in which B15 was stimulated $(10 \mathrm{~Hz}, 3.5 \mathrm{sec}$ on, $3.5 \mathrm{sec}$ off) for four $10 \mathrm{~min}$ periods and $5 \times$ $10^{-7} \mathrm{M}$ serotonin was present in the perfusate in the first and third stimulation period. $B$, SCP release in a single experiment in which the MCC was stimulated ( $5 \mathrm{~Hz}, 3.5 \mathrm{sec}$ on, $3.5 \mathrm{sec}$ off, $10 \mathrm{~min}$ duration) along with B15 (10 Hz, $3.5 \mathrm{sec}$ on, $3.5 \mathrm{sec}$ off, $10 \mathrm{~min}$ duration) in the second and alone in the fourth stimulation period.

muscle contractions and enhance the relaxation of contractions via cAMP-dependent mechanisms (Weiss et al., 1978a,b, 1979; Lloyd et al., 1984; Cropper et al., 1990b; Whim et al., 1990). To understand the behavioral role and behavioral capabilities of the two modulatory systems, it is necessary to determine whether the two systems function independently or interact with each other. As a first step toward this end, Lloyd et al. (1984) determined that the SCPs and serotonin were additive rather than synergistic in stimulating cAMP synthesis in the ARC muscle. Consistent with this finding, Brezina et al. (1994) demonstrated that the SCPs and serotonin enhance calcium current in the ARC in an additive manner. However, these experiments did not address the issue of possible presynaptic cross-talk between the two systems. To address this question, we examined the effect of serotonin on peptide release from B15. Figure $7 A$ shows the results of an experiment in which the BUC content of the samples was measured and the motorneuron was stimulated for $10 \mathrm{~min}$ in the reference pattern (in this case, $10 \mathrm{~Hz}, 3.5 \mathrm{sec}$ on, $3.5 \mathrm{sec}$ off) in the four 

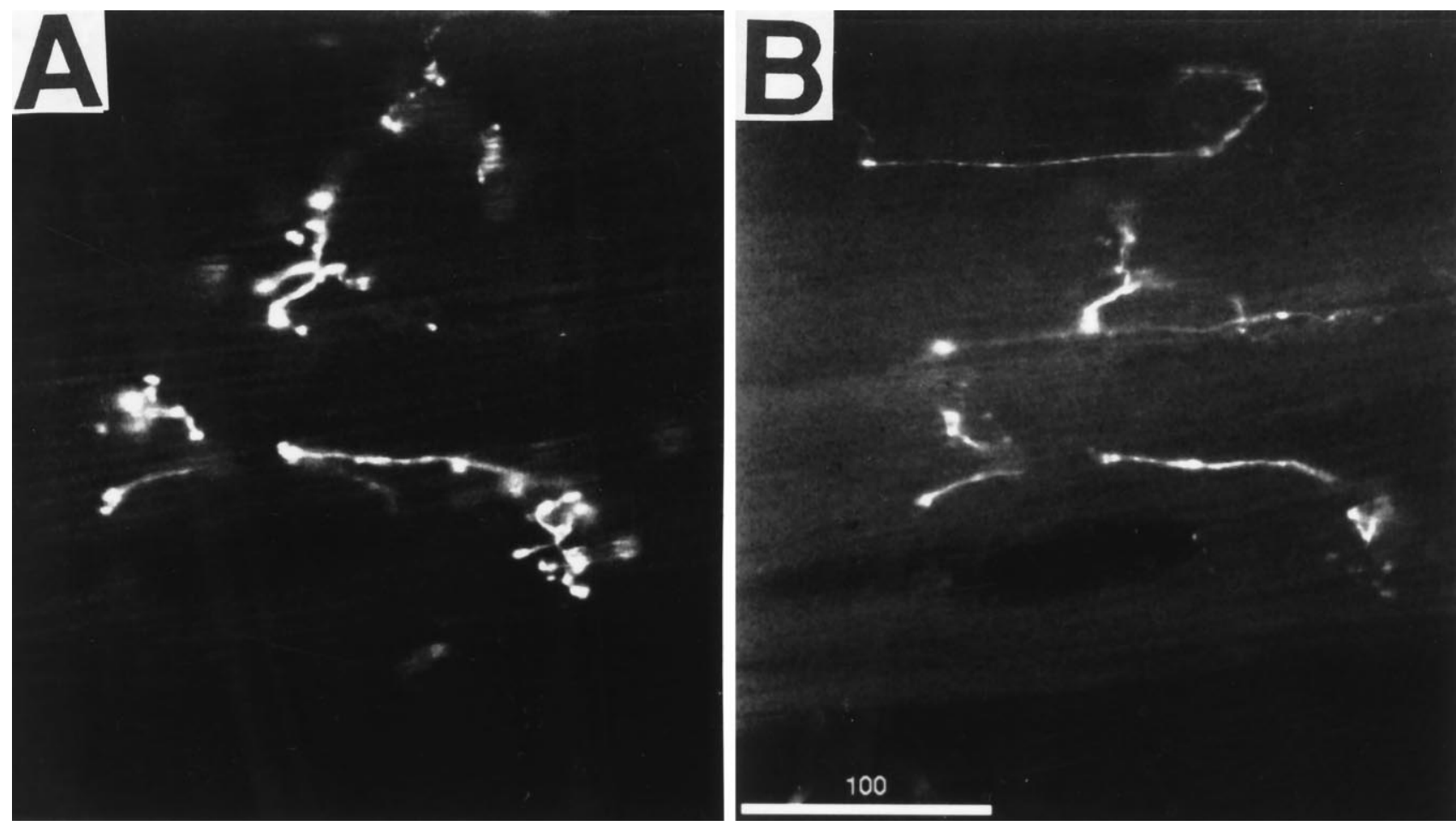

Figure 8. SCP and serotonin immunostaining in whole mounts of ARC muscle. $A$ shows an optical section of an ARC whole mount stained for SCP with a rat antibody and a fluorescein-conjugated donkey anti-rat secondary antibody. $B$ shows the same optical section stained for serotonin using a rabbit antibody and lissamine rhodamine-conjugated donkey anti-rabbit secondary antibody. Some, but not all, SCP-staining varicosities have serotonin staining associated with them, indicating that MCC processes fasciculate with B15 processes and that there may be an opportunity for presynaptic facilitation of transmitter release in some of the B15 terminals. Scale bar, $100 \mu \mathrm{m}$.

periods denoted by the black bars. The release of BUC was noticeably greater in the first and third stimulation periods, when $5 \times 10^{-7} \mathrm{M}$ serotonin was present in the perfusate. Statistical analysis of the results from eight separate experiments (4 measuring each peptide) demonstrated that the increased release of peptides produced by serotonin was statistically significant $(p<$ 0.05). Additional support for the physiological role of serotonin was obtained from experiments in which we investigated the effects of MCC stimulation on peptide release. Figure $7 B$ illustrates the results of an experiment in which we studied the effects of MCC activity on the release of SCP from motorneuron B15. Statistical analysis of the results from four experiments demonstrated that the increased release of peptides produced by MCC stimulation was statistically significant $(p<0.01)$. Because stimulation of MCC alone did not result in peptide release, the action of MCC on peptide release from motorneuron B15 is purely modulatory in that it depends on the firing of neuron B15.

Confocal microscopy was combined with immunocytochemistry to determine whether the presynaptic facilitation of peptide release by the MCC depended on local actions of serotonin or on its diffusion over significant distances. Confocal optical sections of immunocytochemical staining for SCP and serotonin in Figure 8 show that there is significant, but not complete, overlap of the two types of processes in the ARC. This incomplete colocalization also indicates that coprojection is not an artifact of bleed-through between the two fluorophores, because this would result in complete colocalization. These morphological results indicate that there is an opportunity for the MCC to exert local presynaptic actions on B15 terminals in the ARC muscle.

\section{BUC inhibits peptide release}

Previous work demonstrated that high levels of BUC depress ACh release (Phares and Lloyd, 1992) to the point where contractions are virtually eradicated (Cropper et al., 1988, 1990a; Vilim et al., 1994). This may occur when BUCs inhibit ACh release to the point where $\mathrm{ACh}$ is incapable of depolarizing the muscle to the threshold at which the contraction-mediating calcium current is activated (Brezina et al., 1994; Kozak et al., 1996). Because the SCPs, which are coreleased with BUC, act by enhancing the calcium current but do not change the threshold for its activation (Brezina et al., 1994), they are not able to restore muscle contractions under these conditions. Thus, if unchecked, conditions that lead to maximum peptide release could lead to a complete abolition of muscle contractions. One possible way of preventing this situation from happening is to link the inhibition of ACh release to the inhibition of peptide release. Because BUC inhibits ACh release, it is a good candidate for also regulating its own release.

To determine whether BUC could serve as a regulator of peptide release, we investigated the effects of exogenously applied BUC on SCP release. Because our RIA cannot distinguish between native and exogenously applied BUC, SCP measurements were used as indicators of peptide release in general. An ABAtype paradigm was used in which stimulation parameters were identical in all three periods but BUCa was present only in B. The results from a number of experiments were combined by normalizing the release in each period to the ability of the preparation to release peptide cotransmitter. Figure $9 A$ shows the results of a single experiment in which SCP levels of the samples were measured and the motorneuron was stimulated for $10 \mathrm{~min}$ in the 

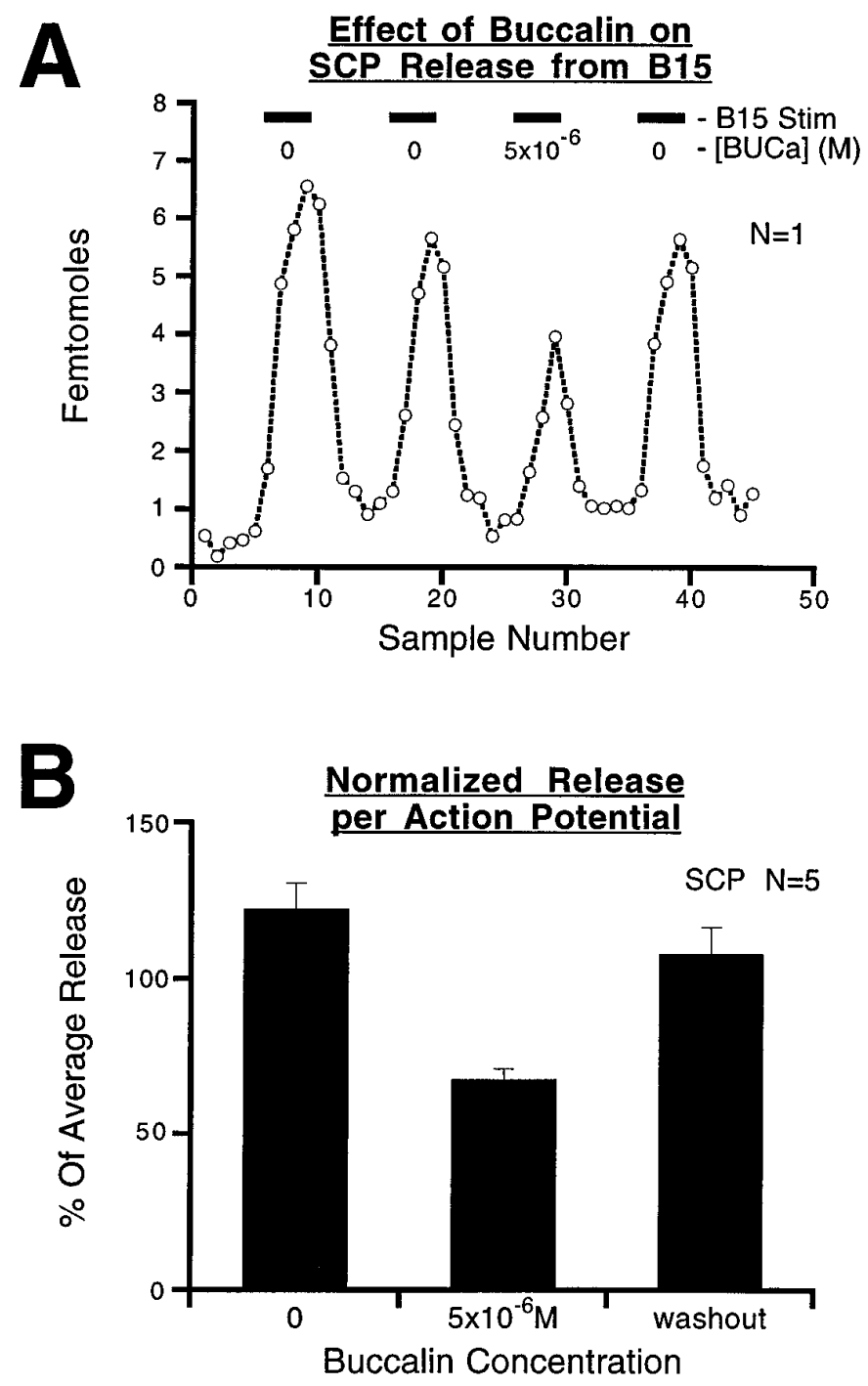

Figure 9. Effect of BUC A on SCP release from $\mathrm{B} 15 . A$, SCP release in a single experiment in which $5 \times 10^{-6} \mathrm{M}$ BUC A was present in the perfusate in the third stimulation period. The stimulation parameters were kept constant in each of the four 10 min stimulation periods (black bars). $B$, The combined results from five experiments in which release is expressed as a percentage of the average release from the periods before, during, and after the application of the BUC A. The bars represent mean $\pm \mathrm{SE}$ for each period. BUC produces a significant $(p<0.01)$ decrease in SCP release that reverses with washout.

reference pattern $(12 \mathrm{~Hz}, 3.5 \mathrm{sec}$ on, $3.5 \mathrm{sec}$ off $)$ in the four periods denoted by the black bars. The release of SCP was noticeably decreased when $5 \times 10^{-6} \mathrm{M}$ BUCa was present in the perfusate in the third stimulation period. The results from five separate experiments were normalized as described above and displayed in Figure 9B. The release of SCP in the presence of BUCa is significantly lower than either the control or the washout periods $(p<0.01)$. The release in the washout period is somewhat (but not significantly) lower than in the control period, perhaps because of incomplete washout of the BUCa.

\section{DISCUSSION}

Because a majority of experiments that have investigated the dependence of cotransmitter release on the parameters of neuronal activity have involved the stimulation of a population of cells rather than a single neuron, the results obtained are difficult to interpret (Andersson et al., 1982; Adams and O'Shea, 1983; Stjarne et al., 1986; Peng and Horn, 1991; Sakaguchi et al., 1991; Peng and Zucker, 1993). Cotransmission involves the release of several substances from a single cell, and unless it can be established that all of the stimulated cells have identical properties, the parametric dependence of cotransmitter release could be interpreted as resulting from differential release from separate populations of axons at different frequencies or, alternatively, could be attributed to presynaptic interactions between different cells. Because normal activity patterns of the neurons that were stimulated in these studies were not characterized, the physiological relevance of the parameters of stimulation that were used remains to be determined. Consequently, the physiological relevance of the tenet that peptide cotransmitters tend to be released at physiologically abnormal high rates of neuronal activity (Hokfelt, 1991) also has to be taken with a certain amount of skepticism.

The ARC preparation enables the direct measurement of peptide release in response to the stimulation of a single motorneuron (see companion paper in this issue) within the range of the motorneuron firing that has been recorded in normally behaving animals (Cropper et al., 1990c). Because current methods directly quantify released peptides and do not depend on indirect arguments, these methods are superior to the ones that were used previously in the ARC (Whim and Lloyd, 1989; Cropper et al., 1990b). The preparation used in the current series of experiments makes it possible to characterize unequivocally the relationship between the release of peptide cotransmitters and physiologically relevant parameters of activity of single neurons. Thus, we have demonstrated that peptide cotransmitters are released under physiologically relevant parameters of stimulation (Vilim et al., 1996). However, in this initial study the motorneurons were stimulated at rates that approached the high end of frequencies recorded in freely moving animals. This left open the possibility that peptide cotransmitters are released only at high rates of neuronal activity. In the present series of experiments, we demonstrated that peptide release occurs throughout the range of motorneuron firing that was recorded in freely moving animals. It is unlikely, therefore, that modulatory cotransmitters function simply as a booster of primary transmitters under extreme conditions of neuronal activity. Peptide release at the spike frequencies observed implies that the peptide cotransmitters are likely to play a role in the generation of normal feeding behavior under physiological conditions.

The fact that in this study, as in the previous one (see companion paper in this issue), partially antagonistic peptides were coreleased in a constant stoichiometric ratio is also inconsistent with the idea that peptide cotransmitters simply function as boosters of the actions of a primary transmitter. Based on the observation that the SCPs and BUCs exert partially antagonistic actions, and the fact that the SCPs modulate the relaxation rate of muscle contractions-something that $\mathrm{ACh}$ is not able to do-we have suggested that modulatory peptides function as a transmission pathway that is parallel to but functionally distinct from the ACh pathway. We have hypothesized (Weiss et al., 1992) that the combined actions of the SCPs and BUCs on contraction amplitude and relaxation allow the occurrence of a greater number of contractions per unit time and for a greater force of contractions (see Fig. 1). These parametric features of feeding behavior vary as a function of hunger and arousal of the animal and are a function of the characteristics of the food the animal is ingesting. Peptides, 
therefore, could serve to maintain feeding efficiency over a wide range of physiological and environmental demands.

A number of studies have provided indirect evidence for the frequency dependence of peptide release (Andersson et al., 1982; Whim and Lloyd, 1989; Peng and Horn, 1991). These studies varied frequency, $\mathrm{BD}$, and IBI concurrently in order to control for the total number of action potentials delivered. We wanted to examine the effects of each of these parameters in isolation and within a physiological range to make sure that any observed changes in peptide release would be behaviorally relevant. We experimentally adjusted contraction amplitude and rate by varying the stimulation parameters of motorneuron firing. Consistent with our hypothesis, we observed that increasing contraction amplitude or rate resulted in increased release of the SCPs and BUCs.

Our hypothesis predicted that, depending on the characteristics of contraction amplitude and rate, the amount of peptides released per contraction should change, but the hypothesis made no predictions as to how the increased release of peptides would be accomplished. When contraction size is increased by increasing the number of spikes (longer BD or higher IF), the amount of peptides released per contraction could increase without increasing peptide release per action potential. In principle, the release per action potential could remain constant or even decrease, and the release per contraction could still increase. In this study, we observed that under conditions that demand higher peptide release, this not only is accomplished by changing the number of action potentials with the release per action potential held constant, but that this process is enhanced by increasing peptide release per action potential. An interesting consequence of this mechanism is that it will result in a more rapid adjustment of the characteristics of muscle contractions to the increased demands for peptide modulation. This interpretation is consistent with the observed actions of the metacerebral cells that fire at high rates at the beginning of the meal, when a rapid transition from the nonaroused to the fully aroused state occurs. These neurons, which on their own exert actions that mimic those of the SCPs, also exert an additional action on the motorneuron terminals, where they facilitate the release of peptides, presumably accelerating the buildup of arousal.

How does the motorneuron terminal "know" how much peptide should be released in order to appropriately adjust the properties of muscle contractions? One possibility is that peptide release is regulated by a factor common to that determining the properties of muscle contraction. A reasonable candidate for such a common variable is the mean rate of motor neuron firing which, in turn, may determine the mean level of calcium in the terminals. We therefore plotted peptide release (per action potential) under the varying parameters investigated in this study as a function of the overall rate of spikes. Figure 10 shows that over a relatively narrow physiological range, peptide release, per spike, is strongly dependent on the mean spike rate and is independent of the exact pattern of firing producing that mean rate. Thus, for example, when the mean rate of spikes was $\sim 3.5 \mathrm{~Hz}$, peptide release per spike was only $20 \%$ of that at the reference level of $6 \mathrm{~Hz}(12 \mathrm{~Hz}$, $3.5 \mathrm{sec}$ on, $3.5 \mathrm{sec}$ off). Because the total number of spikes was kept constant, at a given mean spike rate the exact pattern of firing was different for various experiments (See Fig. 2). Thus, the mean rate of $3.5 \mathrm{~Hz}$ was produced in three ways, by using a low frequency of firing within bursts, by using long IBIs, or by using short bursts. As suggested previously (Peng and Horn, 1991), we found that peptide release depends on the mean rate rather than the specific pattern of motorneuron firing. Furthermore, we found

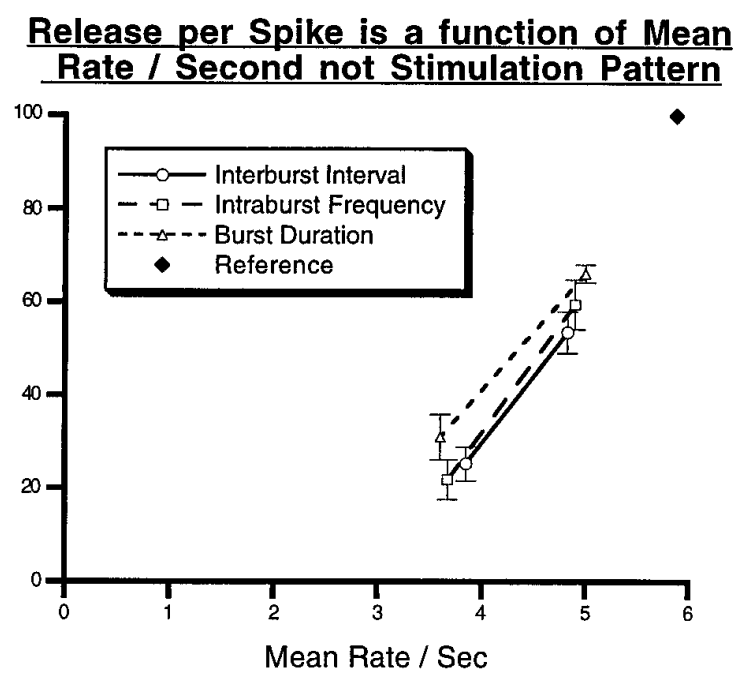

Figure 10. The data from the stimulation parameter experiments (IBI, $\mathrm{IF}$, and $\mathrm{BD}$ ) were re-analyzed by comparing the release in each experiment to the common reference conditions ( $12 \mathrm{~Hz}, 3.5 \mathrm{sec}$ on, $3.5 \mathrm{sec}$ off). Because all of the experiments had the common reference conditions, the results of different experiments could be directly compared. The data were expressed as percent of the release in the reference condition, averaged for like stimulation conditions, and plotted as a function of the average frequency (total action potentials delivered/total seconds) for that condition. In this way, the results from all three stimulation paradigms (IBI, IF, and BD) could be plotted on common axes and compared. The significant overlap in the graphs of the three stimulation paradigms indicates that peptide release is more dependent on the average frequency (mean rate/sec) than on the way in which this average frequency was achieved, at least within the range that is observed in vivo. The black diamond indicates the reference stimulation condition that is shared by all three stimulation paradigms and, consequently, all three lines converge at this point. Extrapolation of these lines to the $x$-axis indicates that they cross at $\sim 3 \mathrm{~Hz}$, suggesting that this is the threshold average frequency for the peptide release from motorneuron $\mathrm{B} 15$.

that peptide release is directly related to mean frequency above a threshold (extrapolated to $\sim 3 \mathrm{~Hz}$ ). This is consistent with the observation of Peng and Zucker (1993) that peptide release is directly related to the time integral of presynaptic calcium elevation above a threshold level. This type of mechanism provides for an automatic way of relating peptide release to muscle contractions, which also are directly related to the mean spike frequency above a threshold value.

This series of studies demonstrates that peptide cotransmitters are released in a graded manner under a variety of experimental conditions that were designed to mimic those observed in normally feeding animals. The graded release of peptides is likely to translate into graded modulation of the characteristics of muscle contractions because a number of studies have demonstrated that peptides act in a dose-dependent manner in this system. The graded control of the release of peptides and of their actions over a broad range of physiologically relevant conditions makes it likely that the normal function of the peptide cotransmitters is to adjust the characteristics of muscle contractions to demands imposed on the system. Thus, the joint action of peptides released from the terminals of motorneuron B15 cannot be easily interpreted as acting as an amplifier of the action of $\mathrm{ACh}$, the primary neurotransmitter. Instead, peptides uniquely modify the characteristics of muscle contractions. We suggest, therefore, that peptide cotransmitters in this system, and perhaps in many other systems, provide a parallel line of transmission of novel information that may be essential for normal behavior. 


\section{REFERENCES}

Adams ME, O’Shea M (1983) Peptide cotransmitter at a neuromuscular junction. Science 221:286-289.

Andersson PO, Bloom SR, Edwards AV, Jaerhult J (1982) Effects of stimulation of the chorda tympani in bursts on submaxillary response in the cat. J Physiol (Lond) 322:469-483.

Brezina V, Evans CG, Weiss KR (1994) Enhancement of Ca current in the accessory radula closer muscle of Aplysia californica by neuromodulators that potentiate its contractions. J Neurosci 14:4393-4411.

Cohen JL, Weiss KR, Kupfermann I (1978) Motor control of buccal muscles in Aplysia. J Neurophysiol 41:157-180.

Cropper EC, Lloyd PE, Reed W, Tenenbaum R, Kupfermann I, Weiss KR (1987) Multiple neuropeptides in cholinergic motor neurons of Aplysia: evidence for modulation intrinsic to the motor circuit. Proc Natl Acad Sci USA 84:3486-3490.

Cropper EC, Miller MW, Tenenbaum R, Kolks MAG, Kupfermann I, Weiss KR (1988) Structure and action of buccalin: a modulatory neuropeptide localized to an identified small cardioactive peptidecontaining cholinergic motor neuron of Aplysia californica. Proc Natl Acad Sci USA 85:6177-6181.

Cropper EC, Miller MW, Vilim FS, Tenenbaum R, Kupfermann I, Weiss KR (1990a) Buccalin is present in the cholinergic motor neuron B16 of Aplysia and it depresses accessory radula closer muscle contractions evoked by stimulation of B16. Brain Res 512:175-179.

Cropper EC, Price D, Tenenbaum R, Kupfermann I, Weiss KR (1990b) Release of peptide cotransmitters from a cholinergic motor neuron under physiological conditions. Proc Natl Acad Sci USA 87:933-937.

Cropper EC, Kupfermann I, Weiss KR (1990c) Differential firing patterns of the peptide-containing cholinergic motor neurons B15 and B16 during feeding behavior in Aplysia. Brain Res 522:176-179.

Hökfelt T (1991) Neuropeptides in perspective: the last ten years. Neuron 7:867-879.

Horn JP (1992) Integrative role of synaptic co-transmission in the bullfrog vasomotor $\mathrm{C}$ system: evidence for a synaptic gain hypothesis. Can J Physiol Pharmacol 70:s19-s26.

Kozak JA, Weiss KR, Brezina V (1996) Two ion currents activated by acetylcholine in the ARC muscle of Aplysia. J Neurophysiol 75:660-677.

Kupfermann I, Carew TJ (1974) Behavioral patterns of Aplysia californica in its natural environment. Behav Biol 12:317-337.

Lloyd PE, Church PJ (1994) Cholinergic neuromuscular synapses in Aplysia have low endogenous acetylcholinesterase activity and a highaffinity uptake system for acetylcholine. J Neurosci 14:6722-6733.

Lloyd PE, Kupfermann I, Weiss KR (1984) Evidence for parallel actions of a molluscan neuropeptide and serotonin in mediating arousal in Aplysia. Proc Natl Acad Sci USA 81:2934-2937.

Lloyd PE, Kupfermann I, Weiss KR (1987) Sequence of small cardioactive peptide A: a second member of a class of neuropeptides in Aplysia. Peptides 8:179-184.
Lundberg JM, Hökfelt T (1983) Coexistence of peptides and classical neurotransmitters. Trends Neurosci 6:325-333.

Peng Y, Horn JP (1991) Continuous stimuli are more effective than bursts for evoking LHRH release in bullfrog sympathetic ganglia. J Neurosci 11:85-95.

Peng Y, Zucker RS (1993) Release of LHRH is linearly related to the time integral of presynaptic $\mathrm{Ca}^{2+}$ elevation above a threshold level in bullfrog sympathetic ganglia. Neuron 10:465-473.

Price DA, Lesser W, Lee TD, Doble KE, Greenberg MJ (1990) Seven FMRFamide-related and two SCP-related cardioactive peptides from Helix. J Exp Biol 154:421-437.

Phares GA, Lloyd PE (1992) Modulation of ACh release from neuromuscular synapses in Aplysia. Soc Neurosci Abstr 18:469.

Sakaguchi M, Inaishi Y, Kashihara Y, Kuno M (1991) Release of calcitonin gene-related peptide from nerve terminals in rat skeletal muscle. J Physiol (Lond) 434:257-270.

Stjarne L, Lundberg JM, Astrand P (1986) Neuropeptide Y: a cotransmitter with noradrenaline and adenosine $5^{\prime}$-triphosphate in the sympathetic nerves of the mouse vas deferens? A biochemical, physiological, and electropharmacological study. Neuroscience 18:151-166.

Vilim FS, Cropper EC, Rosen SC, Tenenbaum R, Kupfermann I, Weiss KR (1994) Structure, localization and action of buccalin b: a bioactive peptide from Aplysia. Peptides 15:959-969.

Vilim FS, Price DA, Lesser W, Kupfermann I, Weiss KR (1996) Costorage and co-release of modulatory peptide cotransmitters with partially antagonistic actions on the accessory radula closer muscle of Aplysia californica. J Neurosci 16:8092-8104.

Weiss KR, Cohen JL, Kupfermann I (1978a) Modulatory control of buccal musculature by a serotonergic neuron (metacerebral cell) in Aplysia. J Neurophysiol 41:181-203.

Weiss KR, Schonberg M, Mandelbaum DE, Kupfermann I (1978b) Activity of individual serotonergic neurone in Aplysia enhances synthesis of cyclic adenosine monophosphate. Nature 272:727-728.

Weiss KR, Mandelbaum DE, Schonberg M, Kupfermann I (1979) Modulation of buccal muscle contractility by serotonergic metacerebral cells in Aplysia: evidence for a role of cyclic adenosine monophosphate. J Neurophysiol 42:791-803.

Weiss KR, Brezina V, Cropper EC, Hooper S, Miller MW, Probst WC, Vilim FS, and Kupfermann I (1992) Peptidergic co-transmission in Aplysia: functional implications for rhythmic behaviors. Experientia 48:456-463.

Whim MD, Lloyd PE (1989) Frequency-dependent release of peptide cotransmitters from identified cholinergic motor neurons in Aplysia. Proc Natl Acad Sci USA 86:9034-9038.

Whim MD, Lloyd PE (1990) Neuropeptide cotransmitters released from an identified cholinergic motor neuron modulate neuromuscular efficacy in Aplysia. J Neurosci 10:3313-3322. 